\title{
Desenvolvimento e implantação de um Jogo Interativo voltado para crianças com distúrbios articulatórios
}

\author{
Diego de Abreu Porcellis, Marcelo da Silveira Siedler, Mateus Holzschuh \\ ${ }^{1}$ Instituto Federal Sul-Riograndense - campus Bagé (IFSUL) - Bagé - RS - Brasil \\ diegoporcelliseifsul.edu.br, siedler@gmail.com, \\ mateusholzschuh@hotmail.com
}

\begin{abstract}
The present work presents a game to aid the literacy of children with articulatory disorders. This software uses voice recognition techniques associated with playful activities, providing the patient with speech training in an autonomous way and outside the hours of specialized professionals, while generating reports so that professionals can follow the child's performance.
\end{abstract}

Resumo. $O$ presente trabalho apresenta um jogo para auxiliar a alfabetização de crianças com distúrbios articulatórios. Este software usa técnicas de reconhecimento de voz associadas a atividades lúdicas proporcionando ao paciente o treinamento de pronúncia das palavras de maneira autônoma e fora do horário de atendimento de profissionais especializados ao mesmo tempo em que gera relatórios para que profissionais possam acompanhar o desempenho da criança.

\section{Introdução}

Distúrbios articulatórios são alterações na fala como omissões, substituições, distorções, adições ou transposições de sons [Trigo, 2004]. Considerado como uma das mais recorrentes manifestações observadas na fala de crianças que chegam à clínica fonoaudiológica. O distúrbio articulatório é definido como uma perturbação da articulação e a impossibilidade de emitir conscientemente uma frase e não saber substituir uma palavra por outra [Silvestre, 2015].

Na região de Bagé, cidade onde este software está sendo aplicado, tem-se uma grande dificuldade de acesso a atendimento especializado para tratar distúrbio articulatório. $\mathrm{O}$ acesso gratuito a tratamento com fonoaudiólogos é restrito, quando disponível dificilmente o paciente consegue mais que uma consulta por semana, dificultando o desenvolvimento da pronúncia e, consequentemente, o da alfabetização. A redução do aproveitamento escolar dessas crianças aumenta a demanda por métodos que permitam complementar a terapia da fala sem a necessidade da presença de um profissional especializado. Dessa maneira, a abre-se espaço para estratégias pedagógicas que possam usar o potencial das tecnologias de informação e comunicação [Wiener e Campos, 2018]

O presente trabalho apresenta um jogo educacional que visa instigar o aluno a praticar a repetição de fonemas de forma lúdica de maneira a tornar atividades que 
VIII Congresso Brasileiro de Informática na Educação (CBIE 2019)

Anais dos Workshops do VIII Congresso Brasileiro de Informática na Educação (WCBIE 2019)

podem ser consideradas cansativas, em algo prazeroso e estimulante [Bardini et al 2017] e [Dermeval e Bittencourt, 2017].

Em estudos preliminares foram analisados os aplicativos desenvolvidos pela Smarty Ears que são desenvolvidos apenas para a plataforma IOS dificultando o seu acesso e também o aplicativo Fofuuu, que está disponível para Android, mas apresentam limitações na sua versão gratuita.

O diferencial do presente jogo á a participação dos profissionais da instituição parceira de modo a criar uma ferramenta personalizada para o problema dessa instituição, além de ser disponibilizado de forma gratuita para a instituição e seus pacientes. Outro ponto a ressaltar é que, por ser voltado a crianças com outras necessidades educacionais especiais, o aplicativo conta com um diferencial, o aluno não perde quando erra a pronúncia, evitando $\mathrm{o}$ sentimento de frustração $\mathrm{e}$, consequentemente, abandono do aplicativo.

\section{Criação do Jogo}

O presente jogo por se tratar de um Serious Games e ter um propósito específico, que neste caso é auxiliar na alfabetização de crianças com distúrbios articulatórios, foi desenvolvido em parceria entre o IFSul - campus Bagé (Instituto Federal Sul-RioGrandense), instituição de ensino onde foi desenvolvido o trabalho, a escola de ensino básico Escola Municipal de Ensino Fundamental General Emilio Luiz Mallet e a instituição de atendimento especializado Caminho da Luz, que possuem sala de recursos e profissionais que atendem regularmente alunos com distúrbio articulatório.

\subsection{Requisitos}

$\mathrm{Na}$ etapa de levantamento de requisitos do jogo foram realizados diversos encontros com os professores e fonoaudiólogos e profissionais das instituições parceiras do projeto além de estudos de ferramentas existentes e resultaram os seguintes requisitos: $O$ jogo será focado na pronúncia de palavras; Deverá ter um sistema de recompensa para estimular os usuários a completar as fases; Deve ter mecânica simples, para abranger o maior número de usuários; Os usuários irão se logar para jogar, podendo ter o acompanhamento dos testes de pronúncia realizados através de um histórico das palavras pronunciadas por cada usuário.

\subsection{Desenvolvimento}

O sistema foi desenvolvido usando o motor de jogo Unity, utilizando a linguagem de programação C\# e dados persistidos em base de dados local usando SQLite, tendo sua estrutura composta dos seguintes elementos:

- Interface de cadastro e configuração do usuário.

- QuickMath - permite praticar a pronúncia de palavras sem precisar jogar.

- Tela de seleção de mundos: compra e seleção dos mundos.

- Seleção de Fase - são seis fases para cada mundo.

- Jogo - usuário pode jogar usando o touch do dispositivo móvel ou teclado.

- Estatística - permite acompanhar o percentual de acerto dos fonemas. 
VIII Congresso Brasileiro de Informática na Educação (CBIE 2019)

Anais dos Workshops do VIII Congresso Brasileiro de Informática na Educação (WCBIE 2019)

\subsection{Mecânica}

O aplicativo foi desenvolvido em duas dimensões (2D) e sua mecânica consiste em controlar um personagem através fases, tendo como objetivo pegar caixas surpresa, fugindo de obstáculos e inimigos que surgem no cenário a medida que o jogo vai transcorrendo. O personagem tem uma barra de vida que diminui cada vez que ele colide com o obstáculo ou recebe algum dano do inimigo e poderá coletar moedas que também podem ser conquistadas por meio da pronuncia correta de palavras ao final de cada fase. Com as moedas é possível comprar um novo "mundo", que apresentará novos desafios.

$\mathrm{Na}$ tela de Configurações é possível classificar o nível de dificuldade dos fonemas apresentados bem como se o aluno é alfabetizado ou não. $O$ jogo utiliza essa configuração prévia para escolher as palavras que o aluno deve pronunciar e se vai estar escrita ou ser através de imagens para crianças não alfabetizadas.

Um dos principais recursos do jogo são os relatórios gerados sobre as palavras pronunciadas. Esse acompanhamento é feito através de uma tela que apresenta a lista de palavras recentemente pronunciadas e o percentual de acerto por fonema, opcionalmente, o responsável pode cadastrar um e-mail para receber um relatório semanal com rendimento do aluno no período.

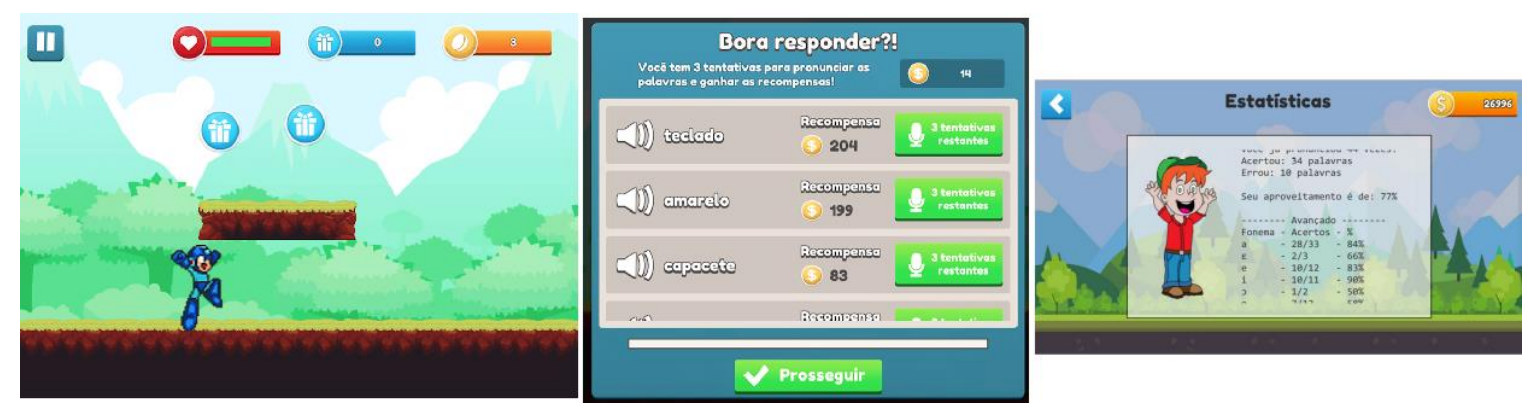

Figura 1. Telas do Jogo

Na figura 1 são apresentadas, respectivamente, a tela de jogo em andamento, pronúncia de palavras e estatística.

\section{Validação}

Para validar o jogo desenvolvido foram realizados testes com profissionais da área de educação inclusiva nas instituições parceiras. Os testes foram realizados em duas etapas como segue:

\subsection{Relevância e funcionalidades}

Nessa etapa, realizada mensalmente, professores e fonoaudiólogos que atuam no atendimento educacional especializado (AEE) das instituições parceiras validaram as implementações desenvolvidas e colaboraram com sugestões para aperfeiçoar o jogo desenvolvido, dentre as quais pode-se destacar a possibilidade de substituição da palavra escrita por imagem, permitindo que alunos não alfabetizados possam usar a ferramenta, customização dos fonemas, centralização da pronúncia ao final da fase (originalmente a pronúncia ocorria durante o jogo) e implementação da funcionalidade QuickMath, permitindo realizar o teste de pronúncia sem a necessidade de jogar. 
VIII Congresso Brasileiro de Informática na Educação (CBIE 2019)

Anais dos Workshops do VIII Congresso Brasileiro de Informática na Educação (WCBIE 2019)

\subsection{Testes de Jogabilidade}

A realização de testes em cima da mecânica do jogo foi realizada com três turmas do ensino fundamental do município. Essas turmas foram convidadas a conhecer o projeto e testaram o jogo, sendo que para estimular a participação os alunos de cada turma que conseguissem mais moedas ganhavam um prêmio.

O objetivo foi validar se a jogabilidade está de acordo com o público alvo do projeto. Desta validação foram realizados ajustes em algumas fases, pois observou se que o grau de dificuldade crescia muito quando o usuário passava da fase três para a quatro. Alguns obstáculos do cenário também foram alterados, pois em alguns testes o personagem ficou preso no cenário.

\section{Conclusão}

O presente trabalho vem para oferecer uma jogo digital para que os alunos com distúrbios articulatórios possam exercitar a pronúncia de fonemas de forma estimulante e divertida, colaborando no processo de alfabetização desses alunos.

A implantação do jogo nas instituições parceiras ocorreu com sucesso, com a integração do Unity com a API Speech to Text ocorrendo satisfatoriamente nos diferentes sistemas operacionais testados (Windows 10, Android 4.4 ou superior) permitindo que os profissionais do atendimento especializado possa usar a ferramenta em suas aulas e acompanhe a evolução dos alunos.

Atualmente o projeto está sendo usando na sala de recursos das duas instituições parceiras, como trabalhos futuros pretende-se desenvolver mais fases e mundos de modo a deixar sempre mais atrativa ao aluno, implementando roteiros para os cenários criados, trazendo as palavras e imagens contextualizadas em narrativas que estimulem a criança a praticar os fonemas propostos.

\section{Referências}

Bardini, A. et al. Aplicativo Lúdico-Pedagógico para Ensino de Programação e Robótica Educacional. In: Anais dos Workshops do Congresso Brasileiro de Informática na Educação. 2017. p. 222.

Dermeval, D.; Bittencourt, I. I. Authoring gamified intelligent tutoring systems. In: Anais dos Workshops do Congresso Brasileiro de Informática na Educação. 2017. p. 14

Silvestre, M. P. (2015) "Desenvolvimento de um sistema de apoio ao tratamento de pacientes com desvios fonológicos para plataforma android", Trabalho de Curso (Graduação em Ciência da Computação), Fundação de Ensino "Eurípides Soares da Rocha” - UNIVEM, Marília, 2015.

Trigo, M. F. (2004) "Sobre os Distúrbios Articulatórios: A Heterogeneidade em questão na clínica de linguagem”, Estudos Lingüísticos XXXIII, p. 1250-1255, 2004, PUC/SP.

Wiener, A.; Campos, C. Colligo App: gamificação em sala de aula. In: Anais dos Workshops do Congresso Brasileiro de Informática na Educação. 2018. p. 272. 